\title{
HIV seroprevalence and its relation to bone infection, bone tumours and limb reconstruction patients in a South African tertiary hospital
}

\author{
Kruger $\mathrm{N}^{1}$, O’Connor $\mathrm{M}^{2}$, Ferreira $\mathrm{N}^{3}$, Marais $\mathrm{LC}^{4}$ \\ MBChB (UCT), MSc (t) Diag Imaging (OXON), MSc (res) Orth (OXON); Orthopaedic registrar, University of Cape Town \\ MBChB; Orthopaedic registrar, University of KwaZulu-Natal \\ 3 BSc, MBChB, FC Orth (SA), MMed (Orth), PhD; Division of Orthopaedic Surgery, Department of Surgical Sciences, Faculty of Medicine and Health Sciences, \\ Stellenbosch University \\ MBChB, FCS Orth (SA), MMed Orth, PhD; Head Clinical Unit, Department of Orthopaedics, Grey's Hospital, School of Clinical Medicine, University of \\ KwaZulu-Natal
}

Corresponding author: Dr Neil Kruger, Division of Orthopaedics, Department of Surgery, University of Cape Town, H49, Old Main Building, Groote Schuur Hospital, Observatory, Cape Town, 7925; Tel: 021404 5108; Cell: 079 3782480; Email: neilkruger6@gmail.com

\begin{abstract}
Background: HIV infection causes a relative immunodeficient state, potentially predisposing patients to osseous infection. It is also associated with non-AIDS defining cancers, and has been described in patients with limb girdle sarcomas and malignant fibrohistiocytic tumours. HIV is further known to suppress cells important in bone healing; however, it is unclear whether bone tumours and mal- or non-unions are more prevalent in patients with HIV. This study aimed to determine the HIV seroprevalence of patients attending a tumour, sepsis and reconstruction (TSR) unit, and explore its relationship to bone infection, bone tumours and patients undergoing limb reconstruction.

Methods: A retrospective review of all adult patients treated over a three-year period was performed. Patients were stratified according to pathology into bone infection, bone tumour, and limb reconstruction categories. Each patient had an opt-in HIV test as part of routine workup. Recruitment, prevalence and statistically significant relationship were then calculated relative to the HIV-uninfected cohort.

Results: Nine-hundred-and-six patients were included, $21.3 \%$ of whom were HIV positive. There were 313 patients with bone infection, 263 patients with bone tumours, and 330 limb reconstruction patients. All groups were similar in HIV prevalence. There was no statistically significant difference between the HIV-positive or -negative patients in any of the groups.

Conclusion: This series found no significant difference in the incidence of bone infections, bone tumours or the need for limb reconstruction, between HIV-positive and -negative patients.
\end{abstract}

Level of evidence: Level 4

Key words: HIV, chronic osteomyelitis, bone infection, tumour, limb reconstruction, osteosarcoma, non-union, deformity

Citation: Kruger N, O'Connor M, Ferreira N, Marais LC. HIV seroprevalence and its relation to bone infection, bone tumours and limb reconstruction patients in a South African tertiary hospital. SA Orthop J 2017;16(4):20-23. http://dx.doi.org/10.17159/2309-8309/2017/v16n4a2

Editor: Prof Anton Schepers, University of the Witwatersrand

Received: September 2016 Accepted: April 2017 Published: November 2017

Copyright: (c) 2017 Kruger N, et al. This is an open-access article distributed under the terms of the Creative Commons Attribution Licence, which permits unrestricted use, distribution and reproduction in any medium, provided the original author and source are credited.

Funding: No funding was received.

Conflict of interest: All authors declare they have no conflicts of interest. 


\section{Introduction}

Infections with the human immunodeficiency virus (HIV) remain an epidemic in Southern Africa. Mid-year population estimates from 2013 indicate 10\% of the almost 53 million people in South Africa are infected with HIV. ${ }^{1}$ KwaZulu-Natal has the highest infection rate with over $21 \%$ of adults between the ages of 15 and 49 years infected. ${ }^{2}$ Furthermore, the virus's primary effect of immunodeficiency predisposes to protean disorders that affect all body systems. Naturally in-hospital seroprevalence rates reflect this, with some 23$32.8 \%$ of inpatients HIV positive. ${ }^{3-5}$

HIV management has advanced significantly over the last 20 years, chiefly through the advent of antiretroviral medication. This has restored immunocompetency such that there is an increased longevity and overall life quality. ${ }^{6}$ Despite these advancements it remains a relative immunodeficient state with increased susceptibility to infections and tumours. ${ }^{7,8}$ Most notably in relation to skeletal disease, HIV suppresses lymphocytes and macrophages that are known to be important in both bone healing ${ }^{9,10}$ and resistance to bacterial infection, ${ }^{11}$ potentially making patients more susceptible to osseous infections, delayed unions, malunions and non-unions.

South Africa's high burden of trauma further exacerbates these issues. Motor vehicle collisions and interpersonal violence account for the majority of injuries, ${ }^{12}$ frequently resulting in open or closed fractures that require internal or external fixation. This places a great number of people at risk of skeletal infection and similarly increases the likelihood of patients requiring limb reconstruction.

The relationship between HIV infection and bone infection, bone tumours or the requirement for limb reconstruction is difficult to accurately elucidate, and consequently is not well defined. First, accurate recording of HIV seroprevalence is not simple. Many studies reflect low recruitment rates, ${ }^{3,13-15}$ often because of stigma or fear of the disease, skewing true prevalence rates. Specific to infection, it remains unclear if HIV infection results in an increased risk for the development of chronic osteomyelitis. Older studies suggest an increased risk of infection in HIV-seropositive individuals treated with internal fixation for open ${ }^{16,17}$ and closed $^{18}$ fractures, while more recent literature has noted no difference or contraindication to internal fixation in open or closed fractures..$^{19,20}$

The question of accurate quantification of HIV seroprevalence in the orthopaedic population and its relation to chronic biofilm-based infections, bone tumours or the requirement for limb reconstruction remains unresolved. This study aimed to investigate HIV seroprevalence in a tertiary tumour, sepsis and reconstruction (TSR) unit and explore its relationship to bone infection, bone tumours and patients undergoing limb reconstruction.

\section{Materials and methods}

We performed a retrospective review of a cross-sectional cohort of patients treated at the TSR unit of a tertiary referral centre that drains the greater part of northern and western KwaZulu-Natal. Ethical approval was obtained from the institutional ethics committee before commencement of the study. All patients that were treated between 1 August 2011 and 1 August 2014 were included. Eligible patients were identified from a prospectively collected database. Patients were excluded if they were under 18 years of age or had an arthroplastyrelated periprosthetic infection.

All patients seen were host stratified, with an opt-in HIV test part of the routine work up. HIV status was recorded where permission for the test was obtained. A positive diagnosis was subsequently affirmed with an ELISA, and appropriate staging, post-test counselling and initiation of therapy where appropriate, begun.

Patients were stratified according to pathology into bone infection, bone tumour, and limb reconstruction categories. The bone infection category included all cases of chronic osteomyelitis, defined by
Waldvogel and Lew as bone infection being present for more than ten days' duration. ${ }^{21}$ Cases of osteoarticular tuberculosis were also included. The tumour category included benign and primary malignant bone tumours, secondary metastases and soft tissue sarcomas of the limbs and limb girdles. Limb reconstruction patients consisted of aseptic mal- or nonunions, and other limb alignment and length discrepancies requiring deformity correction or bone transport.

HIV status was recorded and expressed as prevalence in percentage. Any relationship per diagnostic category was then assessed using Pearson's chi-squared test. The null hypothesis was that there was no significant difference between the groups, with a p-value significance level set to 0.05 .

\section{Results}

A cohort of 906 consecutive adult patients was identified from the prospectively collected database. Of these, 193 patients (21.3\%) were HIV positive, 597 patients (65.9\%) were HIV negative and 116 patients (12.8\%) recorded an unknown status (Figure 1). A total of 790 patients gave consent to be tested, resulting in $87.2 \%$ recruitment.

Further, there were approximately equal numbers of patients in each of the three pathological categories. Three-hundred-andthirteen patients (34.6\%) were treated for bone infection, 263 patients $(29.0 \%)$ were treated for primary or secondary tumours of bone or soft tissue sarcomas, and 330 patients (36.4\%) underwent some form of limb reconstruction (Figure 2).

The HIV prevalence in each pathology category was also similar. In the infection group, 77 (24.5\%) were HIV positive, 202 (64.6\%) HIV negative and 34 (10\%) were HIV unknown. In the tumour group, 53 (20.6\%) were HIV positive, 177 (67.3\%) HIV negative and 33 (12.6\%) were HIV unknown. In the limb reconstruction group, 63 (19.1\%) were HIV positive, 218 (66.1\%) HIV negative and 49 (14.8\%) were HIV unknown (Table I).

As demonstrated in the contingency table (Table II), overall there was no significant difference between any of the groups $(p=0.320)$.

When assessing each category relative to the combined others, for each of bone infection, tumours and limb reconstruction there was no significant difference between any of the groups (bone infection $\mathrm{p}=0.225$; tumours $\mathrm{p}=0.236$; limb reconstruction $\mathrm{p}=0.835$ ).

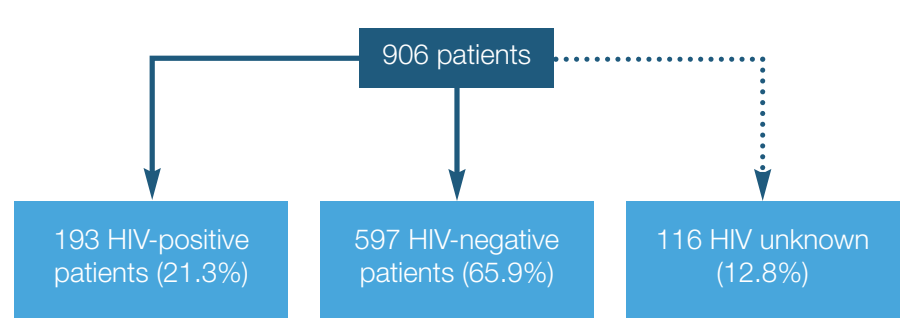

Figure 1. Summary chart showing patient numbers in each HIV status category

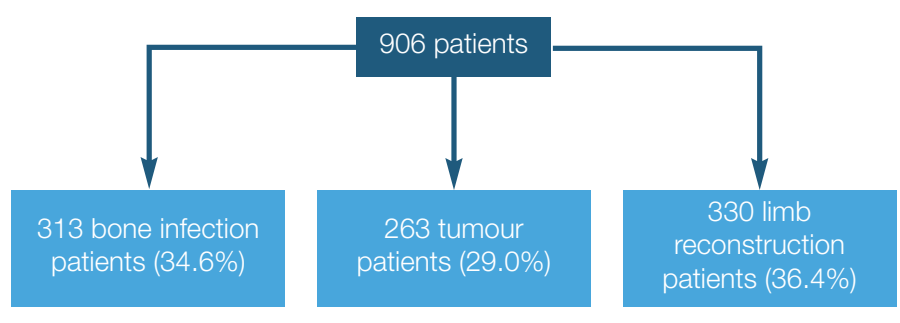

Figure 2. Summary chart showing the number of patients in each pathological category 
Table I: Patient numbers (and percentage) in each of the bone infection, tumour and limb reconstruction categories according to HIV status

\begin{tabular}{|l|c|c|c|}
\hline HIV positive & $\begin{array}{c}\text { Infection } \\
\mathbf{n}(\%)\end{array}$ & $\begin{array}{c}\text { Tumours } \\
\mathbf{n}(\%)\end{array}$ & $\begin{array}{c}\text { Limb } \\
\text { reconstruction } \\
\text { n (\%) }\end{array}$ \\
\hline HIV negative & $202(24.5 \%)$ & $53(20.6 \%)$ & $63(19.1 \%)$ \\
\hline HIV unknown & $34(10.9 \%)$ & $177(67.3 \%)$ & $218(66.1 \%)$ \\
\hline Totals & $\mathbf{3 1 3}$ & $\mathbf{2 6 3}$ & $\mathbf{3 3 0}$ \\
\hline
\end{tabular}

Table II: Contingency table used to calculate Pearson's chi value (highlighted in blue) and the subsequent $p$ value

\begin{tabular}{|l|c|c|c|c|}
\hline \multirow{2}{*}{ HIV } & \multicolumn{4}{|c|}{ Diagnosis } \\
\cline { 2 - 5 } & Infections & Tumours & $\begin{array}{c}\text { Limb } \\
\text { reconstruction }\end{array}$ & Total \\
\hline \multirow{2}{*}{ Positive } & 77 & 53 & 63 & 193 \\
\hline \multirow{2}{*}{ Negative } & 1.6 & 0.2 & 0.8 & 2.5 \\
\hline \multirow{2}{*}{ Unknown } & 202 & 177 & 218 & 597 \\
\hline \multirow{2}{*}{ Total } & 0.1 & 0.1 & 0.0 & 0.2 \\
\hline & 34 & 33 & 49 & 116 \\
\hline
\end{tabular}

\section{Discussion}

The aim of this study was to determine the prevalence of HIV infection in a cohort of patients diagnosed with chronic bone infection, bone tumours or conditions requiring limb reconstruction. The overall HIV prevalence was $21.3 \%$, but importantly there was no statistically significant difference in HIV prevalence for any of the pathological categories, suggesting that HIV infection does not increase the risk for these conditions. This study also reflected an $87.2 \%$ recruitment rate, which strengthens its extrapolation to the broader public.

This recruitment is most likely due to the widespread public awareness campaigns that have resulted in increased awareness of HIV, demystifying much of the unknown about the disease and reducing the associated stigma. ${ }^{22}$ This, combined with the knowledge that more effective treatment has become available, probably increased the willingness of patients to undergo HIV testing.

The association between HIV infection and chronic osteomyelitis is not well defined. Several conflicting studies have been published. Initial reports noted an increased risk of post-operative infection while more recent studies failed to support these findings. In 1991 Hoekman et al. found an increase in the risk of post-operative infection following surgical fracture fixation in symptomatic (defined as CDC stage III or IV) HIV-infected individuals. ${ }^{18}$ Jellis reported a $33 \%$ infection rate following internal fixation of closed fractures and a $72 \%$ infection rate in open fractures. ${ }^{23}$ Noteworthy is the fact that Jellis reported an increase in adult haematogenous osteomyelitis and late implant-related infections as patients' immune competency decreased. ${ }^{23}$ In 2002 Harrison et al. also found a significant increase in early wound infection following open fractures in HIV-positive patients. ${ }^{17}$ The incidence of early wound sepsis following internal fixation of closed fractures was however not increased in this series. Harrison and colleagues then also investigated the prevalence of late infection and found no implant-related infection in 26 HIVpositive patients, at one year follow-up. ${ }^{24}$
A subsequent study, from the same centre in Malawi, again failed to show an increased risk of early wound infection in clean surgery, but found that the infection rate had doubled in contaminated wounds. ${ }^{20}$ Contrary to the findings of Jellis, this study did not show an increase in chronic infections in HIV-positive patients. Two further studies from KwaZulu-Natal, South Africa, added to the controversy. The first noted an increased risk of infection in open fractures in patients with advanced HIV disease (CD4 < 350 cells $/ \mu$ l). ${ }^{19}$ The second study failed to show an increase in early wound infection in HIV-positive patients with open tibia fractures. ${ }^{25}$

The evidence available, therefore, appears to be contradictory in terms of the development of infection in both open and closed fractures. However, most of these studies were designed to look at HIV as a risk factor for early wound infection rather than the development of chronic osteomyelitis. Moreover, it is not known if HIV infection resulted in an increased risk of reactivation of chronic haematogenous osteomyelitis. The results of our study appear to indicate that HIV is not a risk factor for developing chronic osteomyelitis.

Several malignant tumours have been associated with HIV/AIDS including the AIDS-defining cancers (ADCs) such as Kaposi's sarcoma, non-Hodgkin's lymphoma and cervical cancer. ${ }^{26}$ The relative incidence of certain non-AIDS defining cancers (NADCs) have also increased, including Hodgkin's lymphoma, liver, lung, anal and skin cancer. ${ }^{27}$ In addition, HIV is associated with an increased risk for the development of plasma cell disorders like multiple myeloma. ${ }^{28}$ In terms of sarcomas other than Kaposi's, it appears that leiomyosarcoma and angiosarcoma may occur disproportionately in HIV-positive patients. Furthermore, osteosarcoma, rhabdomyosarcoma and malignant fibrohistiocytic tumours have been reported in HIV-positive patients. ${ }^{29}$ In this series, however, the overall incidence of bone and soft tissue tumours was not increased in the HIV-positive group. It is, however, still possible that the prevalence of certain tumours may be increased in the HIV-positive group and this effect may be hidden by the increased incidence of other tumours in age groups with a lower HIV prevalence. Further research is required in this regard.

Limb reconstruction cases generally consisted of non-union, malunion and bone defect management. HIV infection has traditionally been implicated as a risk factor for non-union development but the evidence remains contradictory. Union rates between HIV-positive and HIV-negative patients who sustained closed fractures appear comparable. ${ }^{30,31}$ Union rates following open fractures, however, is more controversial. Chandanwale et al., and Aird et al. both found an increased risk of non-union in HIV-positive patients compared to HIV-negative patients. ${ }^{30,32}$ The current series failed to show that HIV-infected individuals required more limb reconstruction surgery when compared to HIV-negative individuals.

There are some limitations of this study that need to be noted. Data with regard to epidemiology and the specific diagnosis was incomplete and thus not included in the analysis. The lack of CD4 count data represents a shortcoming as previous studies have suggested an increased rate of infection in patients with very low CD4 counts. Subgroup analysis by CD4 count may have shown an increased incidence of chronic osteomyelitis in the severely immunosuppressed individuals. This risk is somewhat mitigated by the specific hospital policy to place those patients with first diagnoses and low CD4 counts on treatment rapidly. Further, patients with CD4 counts below 350 were not operated on, excepting in emergencies. Hence the absolute number of patients with severe immunosuppression was likely very low.

With respect to tumours, no differentiation between primary and secondary bone malignancies was made. Although our results contrast the literature, which generally purports that HIV increases the risk for development of most cancers, ${ }^{33,34}$ it is possible that the study group contained a low number of patients with secondary bone tumours, which are the lesions commonly reported to occur with increased frequency in HIV-infected individuals. ${ }^{8}$ 
Lastly, by excluding children, a number of primary osteosarcoma patients was not captured. This is a very difficult group of patients to study due to low absolute numbers, the issues related to consent for HIV testing, and whether HIV infection was acquired perinatally or later (as these are two different groups of patients in and of themselves).

\section{Conclusion}

In this series, we found no significant difference in the incidence of bone infections or tumours, as well as the need for limb reconstruction, between HIV-positive and -negative patients. Current evidence fails to predict an increased rate of complications in HIV-positive patients and therefore it appears reasonable to expect similar complication rates if HIV patients are treated according to standard treatment protocols. Further research in this field is recommended.

\section{Compliance with ethics guidelines}

Ethical approval was obtained from the institutional ethics committee before commencement of the study.

Human rights: All procedures followed were in accordance with the ethical standards of the responsible committee on human experimentation (institutional and national) and with the Helsinki Declaration 1975, as revised in 2008. Informed consent was obtained from all patients prior to undergoing an HIV test.

\section{References}

1. Statistics South Africa. Mid-year population estimates 2013. www.statssa.gov.za. Accessed July 2016.

2. Welz T, Hosegood V, Jaffar S, Batzing-Feigenbaum J, Herbst K, Newel ML. Continued very high prevalence of HIV infection in rural KwaZulu-Natal, South Africa: a population-based longitudinal study. AIDS 2007:21-11:1467-72.

3. Martinson NA, Omar T, Gray GE, Vermaak JS, Badicel M, Degiannis E, Steyn J, McIntyre JA, Smith M. High rates of HIV in surgical patients in Soweto, South Africa: impact on resource utilisation and recommendations for HIV testing. Trans R Soc Trop Med Hyg 2007;101-2:176-82.

4. Bowley DM, Cherry R, Snyman T, Vellema J, Rein P, Moeng S, Boffard $K D$. Seroprevalence of the human immunodeficiency virus in major trauma patients in Johannesburg. S Afr Med J 2002;92-10:792-93.

5. Yeung S, Wilkinson D, Escott S, Gilks CF. Paediatric HIV infection in a rural South African district hospital. J Trop Pediatr 2000;46-2:107-10.

6. Bor J, Herbst A, Newell M, Bärnighausen T. Increases in adult life expectancy in rural South Africa: valuing the scale-up of HIV treatment. Science 2013;339-6122:961-65.

7. Chen $\mathrm{CH}$, Chung $\mathrm{CY}$, Wang $\mathrm{LH}$, Lin $\mathrm{C}$, Lin HL, Lin HC. Risk of cancer among HIV-infected patients from a population-based nested casecontrol study: implications for cancer prevention. BMC Cancer 2015;15:133.

8. Lin CS, Lin C, Weng SF, Lin SW, Lin YS. Cancer survival in patients with HIV/AIDS in the era of highly active antiretroviral therapy in Taiwan: a population-based cohort study. Cancer Epidemiol 2013;37-5:719-24.

9. Colburn NT, Zaal KJ, Wang F, Tuan RS. A role for gamma/delta T cells in a mouse model of fracture healing. Arthritis Rheum 2009;60-6: 1694-703.

10. Hankemeier S, Grassel S, Plenz G, Spiegel HU, Bruckner P, Probst A. Alteration of fracture stability influences chondrogenesis, osteogenesis and immigration of macrophages. J Orthop Res 2001;19-4:531-38.

11. Wagner C, Kotsougiani D, Pioch M, Prior B, Wentzensen A, Hansch GM. T lymphocytes in acute bacterial infection: increased prevalence of CD11b(+) cells in the peripheral blood and recruitment to the infected site. Immunology 2008;125-4:503-509.

12. Brysiewicz P. Trauma in South Africa. Int J Trauma Nurs 2001;7-4: 129-32.

13. Bassett IV, Giddy J, Nkera J, Wang B, Losina E, Lu Z, Freedberg KA, Walensky RP. Routine voluntary HIV testing in Durban, South Africa: the experience from an outpatient department. J Acquir Immune Defic Syndr 2007;46-2:181-86.
14. Kalichman SC, Simbayi LC. HIV testing attitudes, AIDS stigma, and voluntary HIV counselling and testing in a black township in Cape Town, South Africa. Sex Transm Infect 2003;79-6:442-47.

15. Sefeane T, Lukhele M, Ramokgopa M. Seroprevalence of HIV in acute orthopaedic trauma at the Charlotte Maxeke Johannesburg Academic Hospital. SA Orthopaedic Journal 2011;10-2:30-33.

16. Paiement GD, Hymes RA, LaDouceur MS, Gosselin RA, Green HD. Postoperative infections in asymptomatic HIV-seropositive orthopedic trauma patients. J Trauma 1994;37-34:545-50; discussion 50-51.

17. Harrison WJ, Lewis CP, Lavy CB. Wound healing after implant surgery in HIV-positive patients. J Bone Joint Surg Br 2002;84-6:802-806.

18. Hoekman $P$, van de Perre $P$, Nelissen J, Kwisanga B, Bogaerts J, Kanyangabo $F$. Increased frequency of infection after open reduction of fractures in patients who are seropositive for human immunodeficiency virus. J Bone Joint Surg Am 1991;73-5:675-79.

19. Aird J, Noor S, Lavy C, Rollinson P. The effect of HIV on early wound healing in open fractures treated with internal and external fixation. $J$ Bone Joint Surg Br 2011;93-5:678-83.

20. Bates J, Mkandawire N, Harrison WJ. The incidence and consequences of early wound infection after internal fixation for trauma in HIV-positive patients. J Bone Joint Surg Br 2012;94-9:1265-70.

21. Lew DP, Waldvogel FA. Osteomyelitis. N Engl J Med 1997;336-14: 999-1007.

22. Mall S, Middelkoop K, Mark D, Wood R, Bekker LG. Changing patterns in HIV/AIDS stigma and uptake of voluntary counselling and testing services: the results of two consecutive community surveys conducted in the Western Cape, South Africa. AIDS Care 2013;25-2:194-201.

23. Jellis JE. Orthopaedic surgery and HIV disease in Africa. Int Orthop 1996;20-4:253-56.

24. Harrison WJ, Lavy CB, Lewis CP. One-year follow-up of orthopaedic implants in HIV-positive patients. Int Orthop 2004;28-6:329-32.

25. Howard NE, Phaff M, Aird J, Wicks L, Rollinson P. Does human immunodeficiency virus status affect early wound healing in open surgically stabilised tibial fractures?: A prospective study. Bone Joint J 2013;95-B-12:1703-707.

26. Yanik EL, Napravnik S, Cole SR, Achenbach CJ, Gopal S, Olshan A, Dittmer DP, Kitahata MM, Mugavero MJ, Saag M, Moore RD, Mayer K, Mathews WC, Hunt PW, Rodriguez B, Eron JJ. Incidence and timing of cancer in HIV-infected individuals following initiation of combination antiretroviral therapy. Clin Infect Dis 2013;57-5:756-64.

27. Deeken JF, Tjen ALA, Rudek MA, Okuliar C, Young M, Little RF, Dezube BJ. The rising challenge of non-AIDS-defining cancers in HIV-infected patients. Clin Infect Dis 2012;55-9:1228-35.

28. Coker WJ, Jeter A, Schade H, Kang Y. Plasma cell disorders in HIV-infected patients: epidemiology and molecular mechanisms. Biomark Res 2013;1-1:8.

29. Bhatia K, Shiels MS, Berg A, Engels EA. Sarcomas other than Kaposi sarcoma occurring in immunodeficiency: interpretations from a systematic literature review. Curr Opin Oncol 2012;24-5:537-46.

30. Chandanwale A, Nawale S, Bhosale S, Jadhav S, Anantraman C. Fracture healing rate in HIV positive patients in India. XVI International AIDS Conference 2006.

31. Gardner RO, Bates JH, Ng'oma E, Harrison WJ. Fracture union following internal fixation in the HIV population. Injury 2013;44-6: 830-33.

32. Aird J, Noor $S$, Rollinson P. Is fracture healing affected by HIV in open fractures? J Bone Joint Surg Br 2012;94-B(SUPP XIX)-16.

33. Clifford GM, Polesel J, Rickenbach M, Dal Maso L, Keiser O, Kofler A, Rapiti E, Levi F, Jundt G, Fisch T, Bordoni A, De Weck D, Franceschi S, Swiss HIVC. Cancer risk in the Swiss HIV Cohort Study: associations with immunodeficiency, smoking, and highly active antiretroviral therapy. J Natl Cancer Inst 2005;97-6:425-32.

34. Engels EA, Biggar RJ, Hall HI, Cross H, Crutchfield A, Finch JL, Grigg R, Hylton T, Pawlish KS, McNeel TS, Goedert JJ. Cancer risk in people infected with human immunodeficiency virus in the United States. Int J Cancer 2008;123-1:187-94. 